\title{
Wading pools, fading memories - place navigation in transgenic mouse models of Alzheimer's disease
}

\author{
Heikki Tanila* \\ A. I. Virtanen Institute, University of Eastern Finland, Kuopio, Finland
}

\section{Edited by:}

Emma R. Wood, University of

Edinburgh, UK

Reviewed by:

Kathy R. Magnusson, Oregon State

University, USA

Ashok Kumar, University of Florida

USA

\section{${ }^{*}$ Correspondence:}

Heikki Tanila, Professor in Molecular

Neurobiology, A. I. Virtanen

Institute, University of Eastern

Finland, P. O. Box 1627,

Neulaniementie 2, 70211 Kuopio,

Finland.

e-mail:heikki.tanila@uef.fi
The Morris swim navigation task ("water maze") has been a primary research tool to assess hippocampal-dependent spatial learning and memory in rodents for three decades. Originally developed for rats, its application to mouse studies has been a tedious process, but nowadays there are more studies performed with the Morris swim task in mice than in rats. The task has proved to be particularly useful in demonstrating age-related memory impairment in transgenic mouse models of Alzheimer's disease (AD). This review focuses on task details that are most relevant for its application to mouse studies in general and characteristic patterns of impaired performance in Alzheimer model mice as compared with rodents sustaining hippocampal lesions.

Keywords: spatial memory, amyloid-beta, amyloid precursor protein, presenilin-1, tau

\section{INTRODUCTION}

Exactly 30 years ago Richard Morris and colleagues published in an article in Nature on a novel behavioral task for place navigation in rats and demonstrated the sensitivity of the task for hippocampal lesions (Morris et al., 1982). Since then the task has been known as the "Morris water maze" and been employed in thousands of published studies worldwide. Originally meant to be a test for rats, which are good swimmers by nature, it also has been successfully applied more and more often to memory testing in mice, which are innately strictly terrestrial animals. To acknowledge the important three decade milestone of this task, this review aims at giving a critical overview of applications of Morris water maze in testing mouse models of the most important memory disorder of mankind, Alzheimer's disease (AD).

\section{IMPORTANT TECHNICAL DETAILS IN THE TASK}

In fact, the name "water maze" is a misnomer in the strictest meaning of the word, because the task is performed in an open wading pool and not in a labyrinth-like series of pathways. In particular, since one of the earliest modifications of the swim task was to place a walled radial maze inside the wading pool, resulting in a true water maze [usually called a "radial-arm water maze"; (Buresová et al., 1985)], it would be more appropriate to call the original task the "Morris swim navigation task" or simply as the "Morris swim task," as will be done in this review. The test environment consists of a wading pool with a diameter of $120-200 \mathrm{~cm}$ and a movable submerged platform, which can vary from 10 to $15 \mathrm{~cm}$ in diameter, based on animal size. The submerged platform has to be placed close enough to the surface so that a swimming animal will not be able to swim over it without noticing the platform. Several tricks have been used to make sure that the platform really is hidden from the animal. The original trick was to use milk powder to make the water opaque. Because of the bacterial growth this is not an ideal solution, and has been replaced by inorganic white pigment. Another strategy is to avoid any additives in the water by making both the pool and the platform of matt black plastic and provide the room lighting so that light reflects from the water surface. This approach gives a beautiful contrast for video tracking with a white albino rat, but is much less optimal for the most common mouse strain used in place navigation studies, the C57BL/6 mouse. Having marked black mice with a piece of white adhesive tape for years, our lab eventually decided to use a pool made of white plastic and a transparent plastic platform, which combination eventually proved to work. Even though numerous published studies have only utilized a stopwatch to measure the escape latency as a measure of learning in the Morris swim task, this is not acceptable, because of the lack of control for the swimming speed. A good-quality video tracking system is a must for a proper task monitoring. Besides providing a measure of the swim path length for speed calculation, it also yields several other parameters that help identify the strategy and nature of memory impairment of the animal, such as the mean distance from the wall or from the platform, and occupancy near the platform location in the probe trial without the presence of the platform itself.

The standard swim navigation task consists of 3-8 acquisition trials for 3-5 days, with the platform kept in a fixed location. The last trial of the last day is usually a probe trial, without the platform, to see the eventual search bias of the animal. Ideally, the animal would swim in small circles tightly around the former platform location to indicate that it has an established memory of the location. The probe trial can be delayed to or replicated on the next day to reveal more long-term retention of the memory for the specific location. Some details in the task design are fundamentally important for the desired specificity for hippocampal function. First, the starting positions have to vary to make the 
task performance dependent on true navigation and not egocentric response learning. If a constant start position is used, the task performance will no longer be impaired by hippocampal lesion (Eichenbaum et al., 1990). Second, the environment must provide multiple prominent cues for triangulation. On the other hand, a single cue may not be too prominent, because it will easily attract the animal as a beacon. Especially for mice, this prominent cue is the experimenter him- or herself! A not uncommon error for the experimenter is to anticipate picking up the animal and moving toward the platform at the end of the trial, thus providing a strong cue leading to the target. Besides the probe trial for search bias, the original task design also included another control trial, a visible platform variant of the task. Normal performance in this version, with the platform above the water surface or marked with a pole and flag, should imply that the animal is motivated to climb onto the platform, able to master the motor task requirements, and has normal vision. However, with respect to exclusion of visual impairment, the ability to use the visual platform task as a control has been questioned (Lindner et al., 1997). Rats with hippocampal lesions show initial impairment also in the visual platform task (Morris et al., 1982). So the true value of adding this version is somewhat in doubt. More importantly, it makes a big difference whether visual platform task is run before or after the hidden platform task. If run before in the usual way with curtains around the pool to eliminate all distal cues, it encourages the animal to ignore the distal landmarks, which in the next phase become fundamentally important. This task protocol may thus discourage the use of true navigation strategy and favor the development of alternate search strategies, which eventually show up as poor performance in the probe task. Therefore, it would be recommended to run the visible platform task after the hidden platform version or skip that altogether.

\section{THE TASK IS APPLICABLE TO MICE AFTER ALL}

Initial experiences in applying the Morris swim navigation task to mice were so discouraging that it was long speculated that mice, as strictly terrestrial animals, are not capable of learning the task at all. For instance, one hallmark study that directly compared place learning between $\mathrm{C} 57 \mathrm{Bl} / 6$ mice and Long-Evans rats showed mice to be inferior learners in the Morris swim task, even though their performance was equal to rats on a dry radial-arm maze (Whishaw and Tomie, 1996). The authors attributed the inferior performance of mice in the swim task to the better adaptation of rats to swimming. However, there are a number of less well known factors that may account for the poor performance of mice in the Morris swim task even to a greater extent than the simple motor aspect of swimming.

The first important difference in cognitive abilities between mice and rats are robust differences between mouse strains in their learning ability (see Kennard and Woodruff-Pak, 2011 for a recent review). This is a general problem in using mice in cognitive tasks, but especially pronounced in the Morris swim task, because there are strain differences not only in spatial memory per se, but also in visual acuity and the learning pattern (Kennard and Woodruff-Pak, 2011). In fact, one reason why the C57BL/6, among all laboratory mouse strains, has become the most widely used strain in cognitive testing derives from its good performance in place learning tasks, including the Morris swim task (Owen et al., 1997). This mouse strain is also suitable for aging studies, showing impairment in spatial memory between 12 and 24 months of age according to various studies. In contrast, FVB, $129 / \mathrm{Sv}$, and DBA strains, which are often found in genetically engineered hybrid lines, are clearly inferior in spatial learning as measured in the Morris swim task (Kennard and Woodruff-Pak, 2011).

One severe problem with mice, as compared to rats, is that many mice actually avoid the escape platform. If they find it accidentally, they may jump off and continue swimming. This may be partly related to the common habit of picking up mice with a net, which they experience as highly aversive. Furthermore, as worse swimmers than rats, mice occasionally have difficulties in climbing onto the platform. An established solution in mouse pool testing is to give them an extra day of pretraining in an alley that leads to the platform. A second and still largely unsolved problem is that mice often do not display a clear search bias in the probe task. One obvious problem in early studies was the downscaling of the pool size in order to correspond to the difference in body sizes between the rat and the mouse. The use of a pool with a diameter as small as $80-90 \mathrm{~cm}$ resulted in mice swimming in large circles, but maintaining the appropriate distance from the pool wall. Enlarging the pool to almost the same size as used for rats seemed to solve the problem, but only partially. The fundamental problem seems to be that the mice do not develop the habit of swimming in small circles around the presumed platform location in the probe trials like the rats do. Rather, they make a quick search of the presumed location of the platform, and as soon as they fail to find it, they return to the start location or begin to swim toward the experimenter in the hope of getting picked up (Figure 1). Therefore, the most commonly used occupancy-based parameters for assessing spatial memory, such as "time in the target quadrant" or "time in the vicinity of the platform," do not reveal as clear a search bias as corresponding parameters in rats. A recent systematic study comparing the power of various parameters to assess search bias in mice came to the conclusion that the best parameter to assess spatial memory in the Morris swim task is

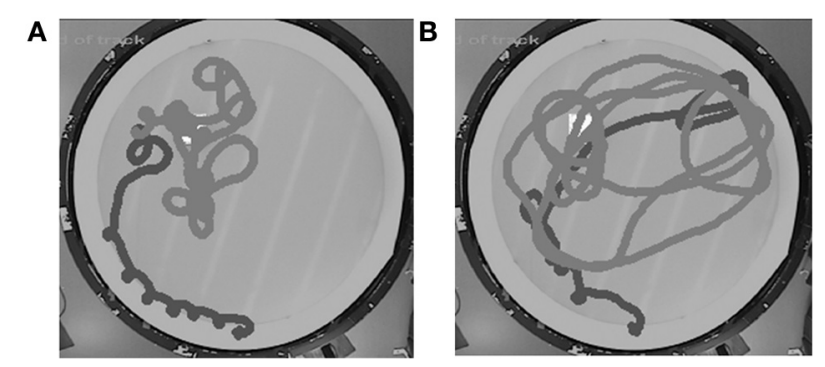

FIGURE 1 | It is unusual for mice to demonstrate the ideal search pattern in the probe test (A). Instead, they usually make one approach to the correct former platform position. As soon as they fail to find the platform, they switch to a wider search pattern, but still show some preference to the original target area (B). Black trace: first $20 \mathrm{~s}$, gray trace: following $40 \mathrm{~s}$. The white square indicates the original platform location. Pool diameter $120 \mathrm{~cm}$. 
the mean distance to the former platform location (Maei et al., 2009).

Finally, the small body size and especially the thin layer of subcutaneous fat, as compared to rats, render mice susceptible to hypothermia during prolonged exposure to the pool water, which is kept close to room temperature for practical reasons and to ensure sufficient motivation to escape from the water. In the first systematic study on this topic, we found to our great surprise that the regular five daily swims in $20^{\circ} \mathrm{C}$ water with $30 \mathrm{~s}$ between the trials was enough to cause up to $9^{\circ} \mathrm{C}$ drop in the rectal temperature (Iivonen et al., 2003). The decline in core temperature was accompanied by slowing of the swimming speed. Moreover, the effect was dependent on the sex and genotype of the mice; females were more susceptible to hypothermia than males and transgenic mice carrying Alzheimer-associated APP and PS1 mutations were more vulnerable than their non-transgenic littermates, because of a smaller body weight. Raising the water temperature from 20 to $24^{\circ} \mathrm{C}$ only partially alleviated the hypothermia. However, increasing the inter-trial interval from $30 \mathrm{~s}$ to $13 \mathrm{~min}$ removed the net cooling effect of five trials on the core temperature and swimming speed. It is nowadays a common practice to allow mice enough time to warm up between the swims and to assist with external heating devices. Nonetheless, vulnerability to hypothermia is a serious limitation in experimental planning. For instance, in the context of aging studies, a long line of evidence suggests that training distributed over several days is less sensitive to agerelated place learning impairment than massed trials (see Foster, 2012 for review). One quite common procedure with aged rats is to give eight trials on one day followed by a probe test $24 \mathrm{~h}$ later. This would be very difficult to adapt to mice, which on the one hand would require more trials than rats to attain the same spatial bias and on the other hand would not tolerate the unavoidable hypothermia induced by such massive water exposure.

\section{MORRIS SWIM TASK HAS BECOME A GOLD STANDARD TEST FOR MEMORY IN AD MOUSE MODELS}

Notwithstanding all the above mentioned precautions, the Morris swim navigation task has become the gold standard in demonstrating spatial memory impairment in mouse models of $\mathrm{AD}$. In contrast to large differences between various transgenic $\mathrm{AD}$ model mice in several common memory tests, such as fear conditioning or object recognition, all established $\mathrm{AD}$ model mice show deficits in the Morris swim task as they age. In addition, the impairment is highly reproducible. We have tested about 3000 APP/PS1 transgenic mice in the Morris swim task during the past 10 years, and have never failed to see an impairment in a test group of transgenic mice, as compared to their wild-type littermates, provided that the mice were past a critical age. Using the terminology for assessing animal models of human disease, one can say that the Morris swim navigation task has face validity, because one of the most prominent everyday problems of $\mathrm{AD}$ patients is easily getting lost outside their home environment. The test can be considered to have construct validity, since transgenic mouse models of $\mathrm{AD}$, whether carrying single APP mutation, combined APP + PS1 mutation, or tau mutation, all display agerelated impairment in the task performance (Table 1). Finally, the task has predictive validity, because all $\mathrm{AD}$ drugs in clinical use at present (rivastigmine, galantamine, donepezil, memantine) show a beneficial effect in the Morris swim task in various mouse models (Sweeney et al., 1988; Minkeviciene et al., 2004; Van Dam et al., 2005, 2008).

\section{DIFFERENT NATURE OF IMPAIRED TASK PERFORMANCE BETWEEN AD MODEL MICE AND RODENTS WITH HIPPOCAMPAL LESIONS}

There are some important differences in the spatial learning deficit in the Morris swim task between transgenic AD model

Table 1 | Summary of genetic mouse models of Alzheimer's disease with reported impairment in the Morris swim navigation task.

\begin{tabular}{|c|c|c|c|}
\hline Transgene & Mouse line & Onset age (months) & References \\
\hline \multicolumn{4}{|l|}{ APP } \\
\hline huAPP751 & APP751 & $<12$ & Moran et al., 1995 \\
\hline APP-CTF & APPC100 & 10 & Berger-Sweeney et al., 1999 \\
\hline APPswe & APP23 & 3 & Van Dam et al., 2003 \\
\hline APPswe & $\operatorname{Tg} 2576$ & 6 & Westerman et al., 2002 \\
\hline APPswe, ind & TgCRND8 & 3 & Chishti et al., 2001 \\
\hline APPind & PDAPP & $<13$ & Daumas et al., 2008 \\
\hline APPswe, ind & J20 & $6-7$ & Palop et al., 2003 \\
\hline \multicolumn{4}{|l|}{$\mathrm{APP}+\mathrm{PS} 1$} \\
\hline APPswe/PS1 (M146L) & APP/PS1 (M146L) & $6-8$ & Trinchese et al., 2004 \\
\hline APPswe/PS1(A246E) & APP/PS1(A246E) & $11-12$ & Puoliväli et al., 2002 \\
\hline APPswe/PS1dE9 & APdE9 & $10-14$ & Minkeviciene et al., 2008 \\
\hline \multicolumn{4}{|l|}{$\mathrm{APP}+\mathrm{PS} 1+$ tau } \\
\hline APPswe/PS1(M146V)/tauP301L & $3 \times T g-A D$ & 4 & Billings et al., 2005 \\
\hline \multicolumn{4}{|l|}{ Tau } \\
\hline P301L tau & $\operatorname{Tg} 4510$ & 1.3 & Santacruz et al., 2005 \\
\hline G272V and P301S tau & THY-Tau22 & $3-10$ & Schindowski et al., 2006 \\
\hline
\end{tabular}

The onset age for the impairment is indicated. 
mice (at least in APP transgenics that have been studied the most) and rodents with hippocampal lesions. First, the learning deficit in transgenic mice is never as severe as in animals with hippocampal lesions, and the transgenic mice are usually able to learn the task if allowed some extra training. In this regard, APP transgenic mice closely resemble aged rats (Foster, 2012). Notably, these statements are largely based on comparison between published studies, since few studies have compared the outcome of an experimental lesion with the pathological changes induced by a genetic manipulation. One demonstrative example is our study from 10 years ago, in which we compared the effects of the APP/PS1 transgenic background and fimbria-fornix transection (FFX) on spatial learning in the Morris swim task in C57BL/6 mice (Liu et al., 2002). While the FFX mice showed practically no improvement during five days, APP/PS1 mice showed a clear learning curve, albeit a slower task acquisition than wild-type littermates. A second difference between transgenic APP mice and animals with hippocampal lesions is in the number of cognitive processes affected. When we compared learning within and between daily sessions, a clear dissociation emerged between APP/PS1 and FFX mice. Whereas FFX mice were impaired in both within and between session learning, APP/PS1 mice showed robust learning within a session, but seemed to forget most of what they learned by the next morning (Liu et al., 2002). This "saw-tooth" learning curve in the Morris swim task is also a common finding in aged rats (Foster, 2012). A parsimonious explanation of this difference is that the hippocampus is necessary for navigation (triangulation based on external landmarks and self-motion) in real time, as well as for episodic encoding and memory consolidation. In contrast, accumulation of amyloid- $\beta$ in the hippocampus interferes only with the long-term memory formation. The susceptibility of APP transgenic mice for faster forgetting of spatial information has been confirmed in at least two other mouse models in later studies (Billings et al., 2005; Daumas et al., 2008). The third difference is that long escape latencies at an early stage of task acquisition in APP transgenic mice are largely due to strong thigmotaxis, which is a prominent feature in genetically modified mice in the Morris swim task in general (Lipp and Wolfer, 1998). This is illustrated in Figure 2, which shows parallel learning curves for 12-month-old APdE9 and wild-type littermate male mice in terms of escape latency (Figure 2A), path length (Figure 2B), and time spent in the wall zone (Figure 2C). On top of strong thigmotaxis, APdE9 mice also show poor search bias in the probe test (Figure 2D). Without any doubt the Morris swim task is a complex one and involves many cognitive processes at the same time, such as general adaptation to the stressful situation, abandoning of an ineffective tendency to search for an escape in the pool wall, locating the submerged platform based on distal landmarks, and finally encoding that information to long-term memory. A human analogy may be to give the task of delivering a package by bike to a remotely known address in a city to a person who has never ridden a bike before. The learning process involves the motor aspect of bike riding, learning how to cope with busy traffic, and finally, by
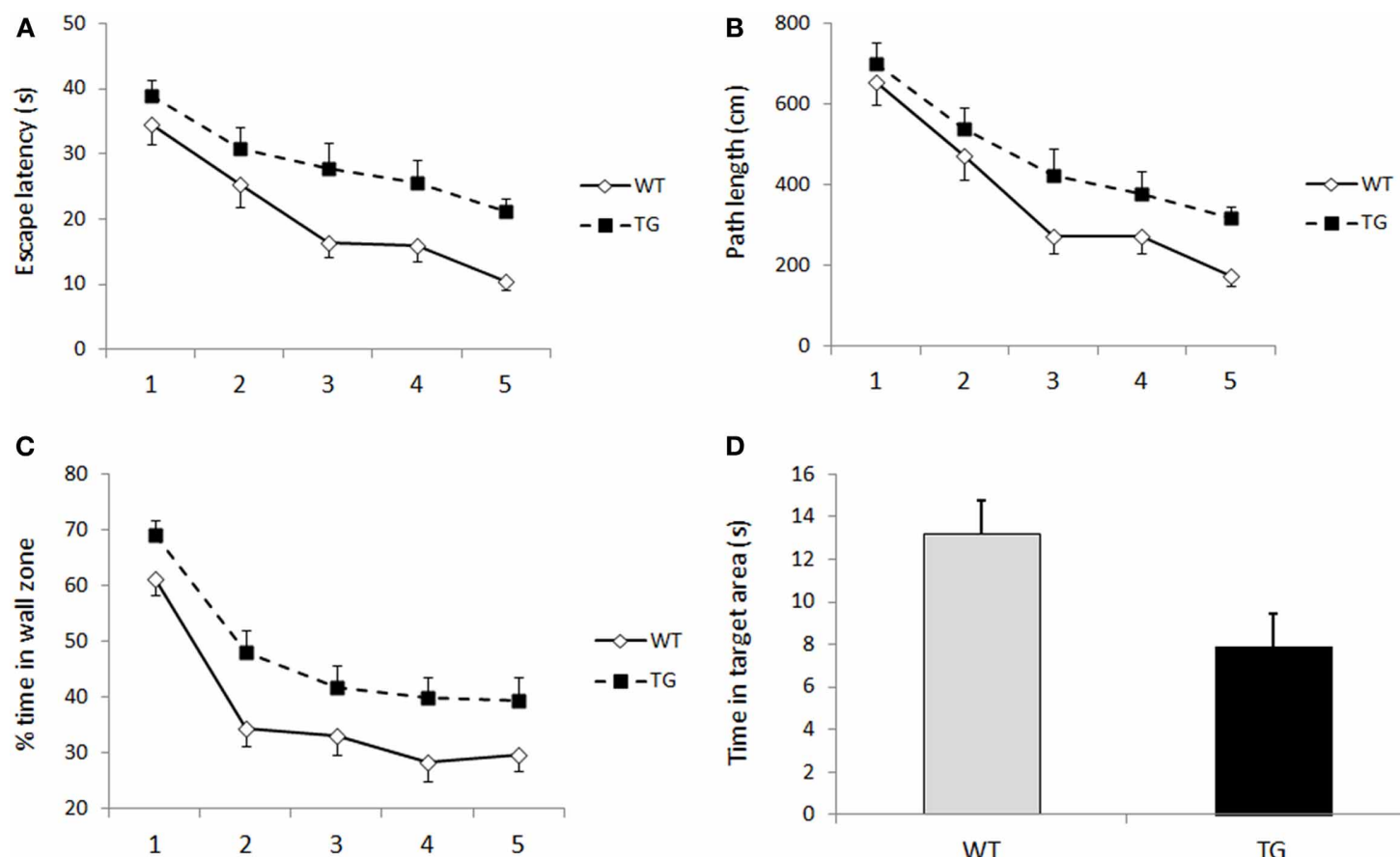

FIGURE 2 | (A) Escape latency over five days of Morris swim task acquisition in 12-month-old male APPSwe/PS1 dE9 (tg, $n=13$ ) mice and their wild-type littermates (WT, $n=15$ ). Genotype difference was significant ( $p=0.001$, ANOVA with repeated measures). Group means and SEMs are shown. (B) Corresponding plot for path length $(p=0.01$, ANOVA with repeated

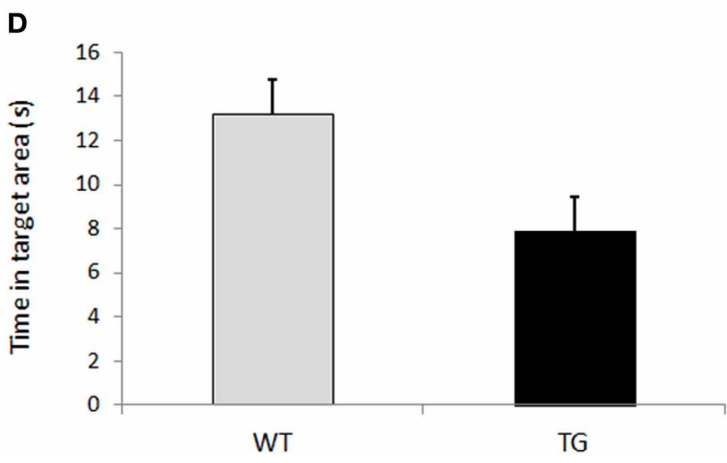

measures). (C) Thigmotaxis, in terms of $\%$ time in the most peripheral $1 / 3$ of the pool area, showed a similar time course as escape latency and path length ( $p=0.001$, ANOVA with repeated measures). (D) The genotypes also differ in the time spent in the former platform area (diameter $30 \mathrm{~cm}$ ) during the probe test on the last trial of day 5 ( $p=0.03$. Student's $t$-test). 
trial and error, to remember successful and unsuccessful routes to the destination in a complex city map. In fact, it may be the feature of the Morris swim task to draw on several parallel cognitive processes that explains its sensitivity to demonstrating cognitive impairment in AD model mice. It is likely that several cognitive processes are compromised in APP transgenic mice due to synaptic pathology involving both the hippocampus and neocortex.

\section{WHICH BRAIN PATHOLOGY ACCOUNTS FOR THE SPATIAL LEARNING IMPAIRMENT IN AD MICE?}

What then is the pathological feature in $\mathrm{AD}$ model mice which accounts for the impaired task acquisition and development of search bias in the Morris swim task? An important feature of all established APP transgenic mouse models is that very young mice ( $\sim 2$ months) are indistinguishable from their wild-type littermates in the task performance. Because the APP transgene is translated to protein already during a late embryonic stage, normal performance in young transgenic mice implies that the behavioral deficit is not due to a developmental abnormality, but rather to age-related neurodegeneration. The same conclusion can be drawn from conditional mutant tau expressing mice (Santacruz et al., 2005). An obvious candidate accounting for the behavioral deficit is amyloid plaque formation. However, the available literature does not support a direct relationship between amyloid plaque formation and spatial memory deficit. Namely, the time course between amyloid plaque formation and the onset of spatial memory deficit varies greatly between different APP transgenic mouse lines. As exemplified in Figure 3, some mouse lines show memory impairment before the first amyloid plaques can be found in a neuropathological examination, while in some other mouse lines these two events can co-occur, and in some other lines, memory impairment may follow amyloid plaque formation by several months.

The poor correlation between amyloid plaque load in postmortem examination and performance in cognitive tests is also a well-established finding in human studies (Nagy et al., 1995).

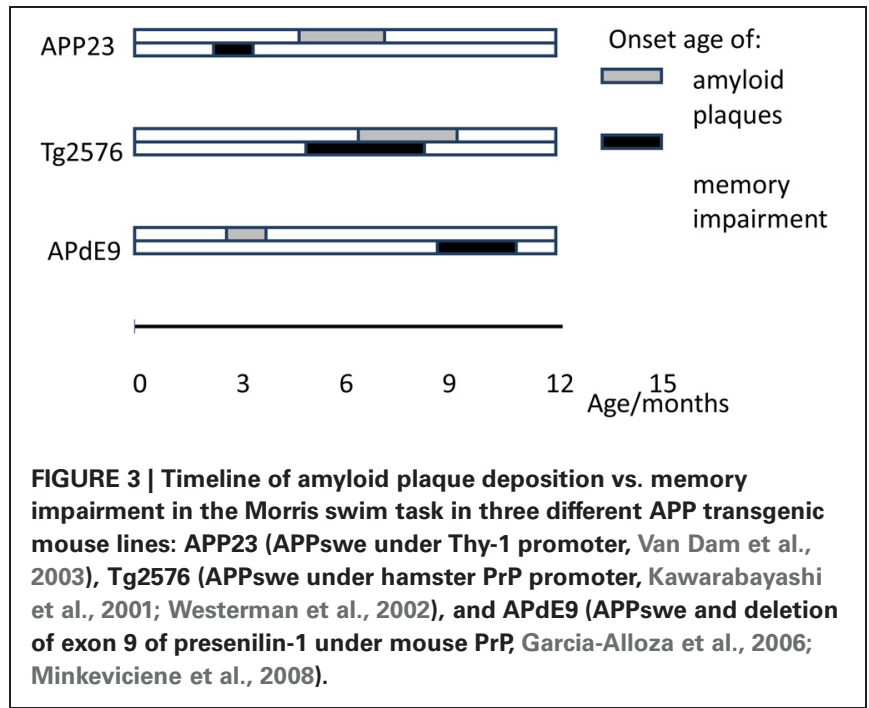

However, it is possible that these different mouse lines exhibit different harmful effects induced by $\mathrm{A} \beta$ formation. For instance, memory deficits before plaque formation may model the impact of soluble $A \beta$ oligomeric species, whereas memory deficits after plaque formation may model the impact of inflammatory mediators around the plaques. An issue that has attracted little attention so far is whether the exact nature of impaired performance in such a complex task as Morris swim navigation also differs between those mouse lines that show early vs. late memory impairment with regard to the appearance of amyloid plaques. Similarly, the correlation between insoluble intracellular tau deposits and impaired Morris swim task performance is not straightforward. Turning off the inducible P301L tau mutant transgene restores the task performance, but if done at a later time point than tau aggregation begins, tau aggregates continue to accumulate in the brain (Santacruz et al., 2005). This finding implies that also for tau aggregates, the soluble species may be the most harmful ones for memory formation.

\section{POTENTIAL AND LIMITATIONS OF THE MORRIS SWIM TASK IN EXPERIMENTAL AD RESEARCH}

As with any test, the Morris swim task has its limitations. It is often criticized for being too stressful for the animals (Kennard and Woodruff-Pak, 2011). This is unavoidable, but the stress level can be reduced by proper pretraining and the use of testing schemes that allow sufficient time for mice to recover between trials. The concern about stressfulness, however, is outweighed by the guaranteed motivation for mice to perform a cognitive task for several days in a row without strict food restriction, which by itself may interfere with the disease process. Another serious limitation is that the classic version of the task is basically a once-a-lifetime learning experience. We have tried to test the same APdE9 mice at a young age before AD pathology and a second time around 12 months of age. Despite several intervening months, the mice show very rapid initial task learning. On the other hand, repeated testing has been successfully applied when mice are trained to criterion using one platform position and then introduced to a new task with a novel platform position repeatedly (Chen et al., 2000). However, this approach is quite tedious and is not well-suited for testing a large number of mice at two different age points. For this purpose, the radial-arm water maze may be a more appropriate solution (Alamed et al., 2006). Nevertheless, because of its established role as the gold standard memory test and the accumulated reference material over the years, the classic Morris swim navigation task is likely to prevail for years as a central tool in the cognitive assessment of $\mathrm{AD}$ model mice, both in studies delving into the disease pathogenesis and studies on the efficacy of new therapeutic interventions. Therefore, knowledge about its use potential and pitfalls should be available in all laboratories working on cognitive assessment of AD model mice.

\section{ACKNOWLEDGMENTS}

Supported by EU 7th Framework program grant HEALTHF2-2007-201159. I wish to thank Susanna Kemppainen for technical assistance in the manuscript preparation. 


\section{REFERENCES}

Alamed, J., Wilcock, D. M., Diamond, D. M., Gordon, M. N., and Morgan, D. (2006). Two-day radial-arm water maze learning and memory task; robust resolution of amyloid-related memory deficits in transgenic mice. Nat. Protoc. 1, 1671-1679.

Berger-Sweeney, J., McPhie, D. L., Arters, J. A., Greenan, J., OsterGranite, M. L., and Neve, R. L. (1999). Impairments in learning and memory accompanied by neurodegeneration in mice transgenic for the carboxyl-terminus of the amyloid precursor protein. Brain Res. Mol. Brain Res. 66, 150-162.

Billings, L. M., Oddo, S., Green, K. N., McGaugh, J. L., and LaFerla, F. M. (2005). Intraneuronal Abeta causes the onset of early Alzheimer's disease-related cognitive deficits in transgenic mice. Neuron 45, 675-688.

Buresová, O., Bures, J., Oitzl, M. S., and Zahálka, A. (1985). Radial maze in the water tank: an aversively motivated spatial working memory task. Physiol. Behav. 34, 1003-1005.

Chen, G., Chen, K. S., Knox, J., Inglis, J., Bernard, A., Martin, S. J., Justice, A., McConlogue, L., Games, D., Freedman, S. B., and Morris, R. G. (2000). A learning deficit related to age and betaamyloid plaques in a mouse model of Alzheimer's disease. Nature 408, 975-979.

Chishti, M. A., Yang, D. S., Janus, C., Phinney, A. L., Horne, P., Pearson, J., Strome, R., Zuker, N., Loukides, J., French, J., Turner, S., Lozza, G., Grilli, M., Kunicki, S., Morissette, C., Paquette, J., Gervais, F., Bergeron, C., Fraser, P. E., Carlson, G. A., George-Hyslop, P. S., and Westaway, D. (2001). Earlyonset amyloid deposition and cognitive deficits in transgenic mice expressing a double mutant form of amyloid precursor protein 695 . J. Biol. Chem. 27, 21562-21570.

Daumas, S., Sandin, J., Chen, K. S., Kobayashi, D., Tulloch, J., Martin, S. J., Games, D., and Morris, R. G. (2008). Faster forgetting contributes to impaired spatial memory in the PDAPP mouse: deficit in memory retrieval associated with increased sensitivity to interference? Learn. Mem. 15, 625-632.

Eichenbaum, H., Stewart, C., and Morris, R. G. (1990).
Hippocampal representation in place learning. J. Neurosci. 10 3531-3542.

Foster, T. C. (2012). Dissecting the age-related decline on spatial learning and memory tasks in rodent models: N-methyl-D-aspartate receptors and voltage-dependent $\mathrm{Ca}^{2+}$ channels in senescent synaptic plasticity. Prog. Neurobiol. 96, 283-303.

Garcia-Alloza, M., Robbins, E. M., Zhang-Nunes, S. X., Purcell, S. M., Betensky, R. A., Raju, S., Prada, C., Greenberg, S. M., Bacskai, B. J., and Frosch, M. P. (2006). Characterization of amyloid deposition in the APPswe/PS1dE9 mouse model of Alzheimer disease. Neurobiol. Dis. 24, 516-524.

Iivonen, H., Nurminen, L., Harri, M., Tanila, H., and Puoliväli, J. (2003). Hypothermia in mice tested in Morris water maze. Behav. Brain Res. 141, 207-213.

Kawarabayashi, T., Younkin, L. H., Saido, T. C., Shoji, M., Ashe, K. H., and Younkin, S. G. (2001). Age-dependent changes in brain, CSF, and plasma amyloid (beta) protein in the $\operatorname{Tg} 2576$ transgenic mouse model of Alzheimer's disease. J. Neurosci. 21, 372-381.

Kennard, J. A., and Woodruff-Pak, D. S. (2011). Age sensitivity of behavioral tests and brain substrates of normal aging in mice. Front. Aging Neurosci. 3:9. doi: 10.3389/fnagi. 2011.00009

Lindner, M. D., Plone, M. A., Schallert, T., and Emerich, D. F. (1997). Blind rats are not profoundly impaired in the reference memory Morris water maze and cannot be clearly discriminated from rats with cognitive deficits in the cued platform task. Brain Res. Cogn. Brain Res. 5, 329-333.

Lipp, H. P., and Wolfer, D. P. (1998). Genetically modified mice and cognition. Curr. Opin. Neurobiol. 8, 272-280.

Liu, L., Ikonen, S., Heikkinen, T., Heikkilä, M., Puoliväli, J., van Groen, T., and Tanila, H. (2002). Effects of fimbria-fornix lesion and amyloid pathology on spatial learning and memory in transgenic APP+PS1 mice. Behav. Brain Res. 134, 433-445.

Maei, H. R., Zaslavsky, K., Teixeira, C. M., and Frankland, P. W. (2009). What is the most sensitive measure of water maze probe test performance? Front. Integr.
Neurosci. 3:4. doi: 10.3389/neuro.07. 004.2009

Minkeviciene, R., Banerjee, P., and Tanila, H. (2004). Memantine improves spatial learning in a transgenic mouse model of Alzheimer's disease. J. Pharmacol. Exp. Ther. 311, 677-682.

Minkeviciene, R., Ihalainen, J., Malm, T., Matilainen, O., KeksaGoldsteine, V., Goldsteins, G., Iivonen, H., Leguit, N., Glennon, J., Koistinaho, J., Banerjee, P., and Tanila, H. (2008). Age-related decrease in stimulated glutamate release and vesicular glutamate transporters in APP/PS1 transgenic and wild-type mice. J. Neurochem. 105, 584-594.

Moran, P. M., Higgins, L. S., Cordell, B., and Moser, P. C. (1995). Age-related learning deficits in transgenic mice expressing the 751-amino acid isoform of human beta-amyloid precursor protein. Proc. Natl. Acad. Sci. U.S.A. 92, 5341-5345.

Morris, R. G., Garrud, P., Rawlins, J. N., and O'Keefe, J. (1982). Place navigation impaired in rats with hippocampal lesions. Nature 297, 681-683.

Nagy, Z., Esiri, M. M., Jobst, K. A., Morris, J. H., King, E. M., McDonald, B., Litchfield, S., Smith, A., Barnetson, L., and Smith, A. D. (1995). Relative roles of plaques and tangles in the dementia of Alzheimer's disease: correlations using three sets of neuropathological criteria. Dementia 6, 21-31.

Owen, E. H., Logue, S. F., Rasmussen, D. L., and Wehner, J. M. (1997). Assessment of learning by the Morris water task and fear conditioning in inbred mouse strains and F1 hybrids: implications of genetic background for single gene mutations and quantitative trait loci analyses. Neuroscience 80, 1087-1099.

Palop, J. J., Jones, B., Kekonius, L., Chin, J., Yu, G. Q., Raber, J., Masliah, E., and Mucke, L. (2003). Neuronal depletion of calciumdependent proteins in the dentate gyrus is tightly linked to Alzheimer's disease-related cognitive deficits. Proc. Natl. Acad. Sci. U.S.A. 100, 9572-9577.

Puoliväli, J., Wang, J., Heikkinen, T., Heikkilä, M., Tapiola, T., van Groen, T., and Tanila, H. (2002). Hippocampal A beta 42 levels correlate with spatial memory deficit in APP and PS1 double transgenic mice. Neurobiol. Dis. 9, 339-347.
Santacruz, K., Lewis, J., Spires, T., Paulson, J., Kotilinek, L., Ingelsson, M., Guimaraes, A., DeTure, M., Ramsden, M., McGowan, E. Forster, C., Yue, M., Orne, J., Janus, C., Mariash, A., Kuskowski, M., Hyman, B., Hutton, M., and Ashe, K. H. (2005). Tau suppression in a neurodegenerative mouse model improves memory function. Science 309, 476-481.

Schindowski, K., Bretteville, A., Leroy, K., Bégard, S., Brion, J. P., Hamdane, M., and Buée, L. (2006). Alzheimer's disease-like tau neuropathology leads to memory deficits and loss of functional synapses in a novel mutated tau transgenic mouse without any motor deficits. Am. J. Pathol. 169, 599-616.

Sweeney, J. E., Höhmann, C. F., Moran, T. H., and Coyle, J. T. (1988). A long-acting cholinesterase inhibitor reverses spatial memory deficits in mice. Pharmacol. Biochem. Behav. 31, 141-147.

Trinchese, F., Liu, S., Battaglia, F., Walter, S., Mathews, P. M., and Arancio, O. (2004). Progressive agerelated development of Alzheimerlike pathology in APP/PS1 mice. Ann. Neurol. 55, 801-814.

Van Dam, D., Abramowski, D., Staufenbiel, M., and De Deyn, P. P. (2005). Symptomatic effect of donepezil, rivastigmine, galantamine and memantine on cognitive deficits in the APP23 model. Psychopharmacology (Berl.) 180, 177-190.

Van Dam, D., Coen, K., and De Deyn, P. P. (2008). Cognitive evaluation of disease-modifying efficacy of donepezil in the APP23 mouse model for Alzheimer's disease. Psychopharmacology (Berl.) 197, 37-43.

Van Dam, D., D’Hooge, R., Staufenbiel, M., Van Ginneken, C., Van Meir, F., and De Deyn, P. P. (2003). Age-dependent cognitive decline in the APP23 model precedes amyloid deposition. Eur. J. Neurosci. 17, 388-396.

Westerman, M. A., Cooper-Blacketer, D., Mariash, A., Kotilinek, L., Kawarabayashi, T., Younkin, L. H., Carlson, G. A., Younkin, S. G., and Ashe, K. H. (2002). The relationship between Abeta and memory in the Tg2576 mouse model of Alzheimer's disease. J. Neurosci. 22, 1858-1867.

Whishaw, I. Q., and Tomie, J. (1996). Of mice and mazes: similarities between mice and rats on dry land 
but not water mazes. Physiol. Behav. 60, 1191-1197.

Conflict of Interest Statement: The author declares that the research was conducted in the absence of any commercial or financial relationships that could be construed as a potential conflict of interest.

Received: 22 March 2012; paper pending published: 16 April 2012; accepted: 15 May 2012; published online: 01 June 2012.
Citation: Tanila H (2012) Wading pools, fading memories - place navigation in transgenic mouse models of Alzheimer's disease. Front. Ag. Neurosci. 4:11. doi: 10.3389/fnagi.2012.00011

Copyright (C) 2012 Tanila. This is an open-access article distributed under the terms of the Creative Commons Attribution Non Commercial License, which permits non-commercial use, distribution, and reproduction in other forums, provided the original authors and source are credited. 